\title{
Proposta de um Jogo Educacional para o Ensino de Estrutura de Dados
}

\author{
Cristiano N. Ferreira, Renan M. Denardi, Ruan C. B. Pozzebon, Gleizer B. Voss \\ ${ }^{1}$ Instituto Federal Farroupilha - Campus São Vicente do Sul \\ São Vicente do Sul - RS - Brazil \\ \{cristianonicola, renanmachadodenardi\} @hotmail.com, \{ruan.pozzebon, \\ gleizer.voss\} @iffarroupilha.edu.br
}

\begin{abstract}
This paper presents a proposal for an educational game focused on teaching and practicing contents related to Data Structures area, which initially will be limited to teaching the structure of data trees. The game enables students to learn in an interactive, challenging and competitive way, since it makes possible for the students to associate class contents with exercises by establishing communication and competition between students. This work is on development stage and aims helping students in knowledge construction for the data structures area, as well as enabling practical applications for knowledge retention.
\end{abstract}

Resumo. Este artigo apresenta a proposta de um jogo educacional voltado para o ensino e prática de conteúdos relacionados à área de Estrutura de Dados, o qual inicialmente será limitado ao ensino da estrutura de dados árvore. Esse jogo permite aos estudantes aprender de maneira interativa, desafiadora e competitiva, pois possibilita aos estudantes, além de associar os conteúdos abordados com a prática de exercícios, estabelecer a competição e comunicação entre os universitários. Este trabalho encontra-se em fase de desenvolvimento e objetiva auxiliar estudantes na construção de conhecimentos na área de estrutura de dados, bem como possibilitar a aplicação prática e solidificação dos mesmos.

\section{Introdução}

Nos últimos anos ocorreram mudanças significativas na forma de se comunicar, bem como de buscar informações e materiais de estudos. No contexto atual a internet possui uma relevante importância na vida das pessoas, geralmente é conectado a ela onde o usuário passa a maior parte do tempo, exercendo diversas atividades. Com a popularização da internet, o acesso a conteúdos didáticos por meio de ferramentas educacionais ampliou-se, possibilitando aos usuários usufruir dessas ferramentas para expandirem seus conhecimentos.

Aproveitando os assuntos mencionados anteriormente, o trabalho relatado no artigo visa propor um jogo educacional voltado especificamente para o ensino e prática da disciplina de Estrutura de Dados, o qual inicialmente será limitado ao ensino da estrutura do tipo árvore. Ele não possui como finalidade substituir aulas presenciais ou cursos voltados à área, mas sim ser uma ferramenta de auxílio para os alunos associarem os conteúdos abordados por meio da prática de exercícios. 
De acordo com Djajalaksana (2011), a metodologia de ensino predominante em cursos superiores são as chamadas aulas expositivas. Esta é uma metodologia muito importante, pois possibilita uma maior interação entre alunos e professores. No entanto, os estudantes acabam encontrando dificuldades em determinados conteúdos, quando apresentados somente desta forma.

Algumas dessas dificuldades são devido a déficits de aprendizagem conduzidos desde a formação básica. Porém outras são devido à falta de prática dos conteúdos abordados em aula, haja vista que, as disciplinas possuem uma ementa que deve ser cumprida e muitas vezes acabam se tornando "engessadas", pois ficam predominantemente presas à teoria, impossibilitando assim, maiores práticas dos conteúdos em sala de aula. O presente trabalho busca suprir essa carência de aulas práticas, mais especificamente da disciplina de Estrutura de Dados.

Considerando o contexto atual, esse trabalho busca contribuir com os estudantes de cursos de graduação da área de computação, especialmente conteúdos da disciplina de estrutura de dados, fornecendo aos mesmos um ambiente para praticar conceitos adquiridos em aulas presenciais ou a distância, para assim solidificar a construção de conhecimentos. Outra colaboração que o jogo visa fornecer é aumentar o networking entre os jogadores (i.e., melhorar os relacionamentos pessoais e o contato entre os mesmos), para assim possibilitar uma maior interação entre estudantes de inúmeros pontos do Brasil e quem sabe futuramente de outros países.

O restante do artigo está organizado da seguinte maneira. A seção 2 apresenta a fundamentação teórica do trabalho. A seção 3 discute trabalhos relacionados. A seção 4 expõe a ideia do jogo, bem como seu funcionamento, enquanto a seção 5 revela a conclusão do trabalho.

\section{Fundamentação Teórica}

Esta seção busca apresentar conceitos sobre os principais assuntos inerentes ao trabalho. Os mesmos serão apresentados em subseções e abordarão temas como metodologia tradicional de ensino, metodologia de ensino através de jogos e estruturas de dados.

\subsection{Metodologia Tradicional de Ensino}

Como já mencionado, a metodologia de ensino predominante são as chamadas aulas expositivas, onde a função dos estudantes é basicamente escutar a fala de seus professores, além de formular possíveis anotações que descrevam em tópicos os conteúdos abordados pelos docentes. Esta metodologia direcionada para o professor faz com que se abra uma lacuna entre os conceitos abstraídos pelos estudantes e a prática dos mesmos (SHAW e DERMOUDY, 2005).

De acordo com Biggs (2011), uma das principais desvantagens de utilizar somente a metodologia com aulas expositivas, é que os estudantes perdem a concentração após aproximadamente 10-15 minutos de aulas com essa metodologia. E isso acaba prejudicando a abstração necessária para a construção do conhecimento.

Já conforme Von Wangenheim (2012), os alunos de hoje representam a geração $\mathrm{Y}$, que demonstra comportamentos interativos e espera um retorno imediato. 
CBIE-LACLO 2015

Anais dos Workshops do IV Congresso Brasileiro de Informática na Educação (CBIE 2015)

Consequentemente, utilizar simplesmente o ensino teórico pode não ser suficiente para o engajamento e a construção do conhecimento desses estudantes.

Aliado a isso, um levantamento realizado no ano de 2012 pelo Sindicato das Entidades Mantenedoras de Estabelecimentos de Ensino Superior no Estado de São Paulo (SEMESP) divulgou que cursos da área da computação são os que possuem o maior índice de evasão de acadêmicos (GLOBO, 2015). No curso de Ciência da Computação, a cada quatro alunos que ingressam no curso, apenas um conclui o mesmo. Essa ampla evasão pode ser causada pela dificuldade de abstração de conteúdos, esses obtidos exclusivamente por aulas expositivas.

Antes, Dale (1946 apud De Andréa Picolli, Spers e De Moraes, 2011) relacionou onze formas distintas de apresentar conteúdos educacionais, classificando as abordagens mais eficientes para assimilação de conteúdos (Figura 1). Pode-se constatar que quanto maior o envolvimento, maior é o potencial de aquisição de conhecimento por parte do aluno (DE ANDRÉA PICOLLI, SPERS e DE MORAES, 2011).

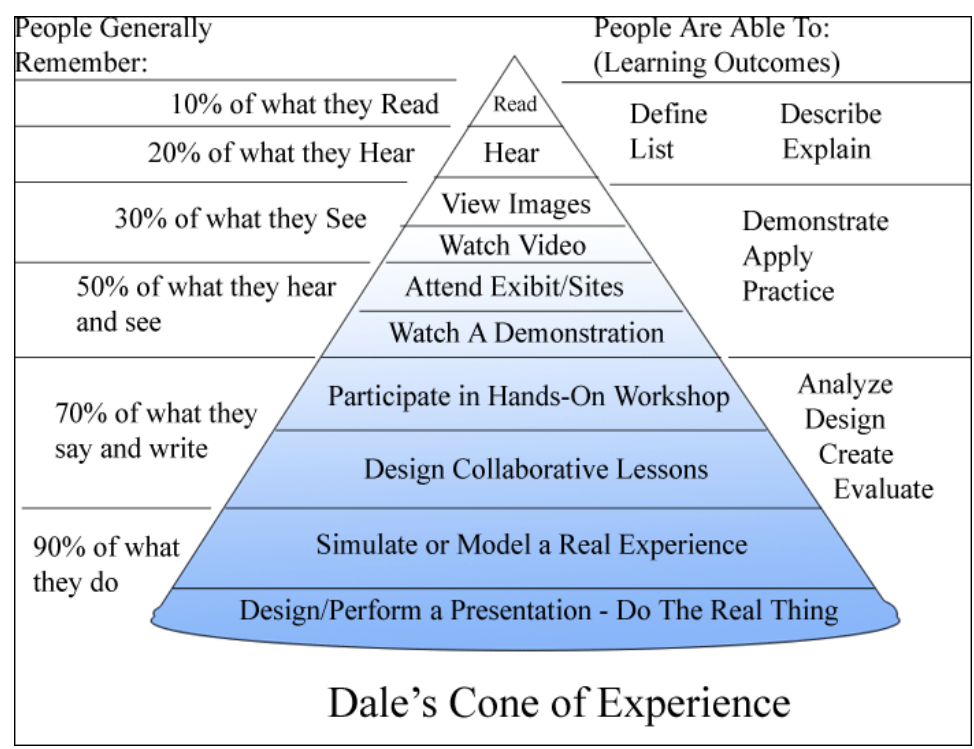

Figura 1. Pirâmide de Aquisição do Conhecimento de Dale (1946 apud De Andréa Picolli, Spers e De Moraes, 2011)

\subsection{Metodologia de Ensino Através de Jogos}

Para fazer com que os alunos aprendam de uma forma mais profunda, existe a necessidade de conciliar a exposição de conteúdo com a prática dos conhecimentos abstraídos. Para satisfazer esse objetivo, além de aulas expositivas, devem ser usados outros métodos voltados para uma aprendizagem ativa (BONWELL e EISON, 1991).

Existem diversas metodologias de ensino, entre essas, destacam-se os jogos, que são considerados uma forma experiencial de ensino (Figura 2) (VON WANGENHEIM, 2012). Para ser considerado um jogo educacional, o mesmo precisa satisfazer duas dimensões. Primeiramente necessita ter uma competição entre adversários e esses devem agir sobre restrições, mas também precisa ser educacional, ou seja, deve ser projetado para ensinar um determinado assunto (DEMPSEY; RASMUSSEN e LUCASSEN, 1996). 
A competição que o jogo possibilita pode ser utilizada como motivação. Uma atitude frequente nos alunos é o desejo de competir e a busca pela vitória. A utilização de jogos fornece esse tipo de recompensa, assim diferenciando-se de outros tipos de metodologias. Conforme Von Wangenheim (2012), os exercícios mais tradicionais precisam, muitas vezes, "valer nota" para assegurar que os alunos façam. Por sua vez, utilizando jogos, o fato de reconhecer os alunos vitoriosos é suficientemente como recompensa, e consequentemente incentiva a realização dos mesmos.

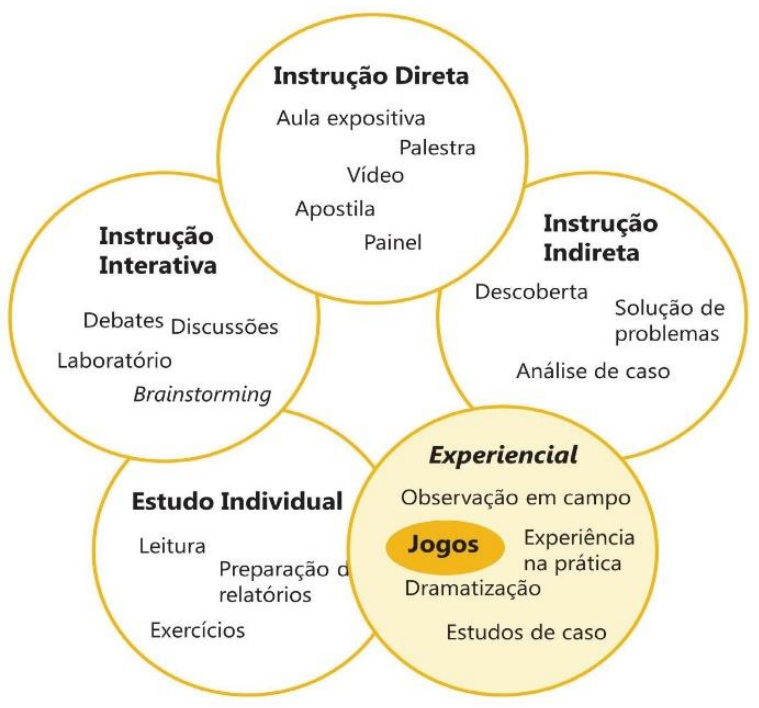

Figura 2. Formas de Ensino (VON WANGENHEIM, 2012)

A capacidade de dar feedback ao aluno informando de uma forma clara onde ele errou ou acertou, com certeza é um ponto favorável para a abordagem com o ensino de jogos. Além disso, eles possibilitam um ambiente seguro para o estudante testar diversas alternativas e verificar as consequências. Assim, aprendendo com seus próprios erros, isso tudo sem sofrer colapsos nervosos ou levar um projeto ao fracasso (PFAHL; KOVAL e RUHE, 2001).

\subsection{Estrutura de Dados}

De acordo com Lafore (2007) uma estrutura de dados é responsável pela organização dos dados seguindo alguma lógica específica, e concede ao usuário determinadas operações para manipulações sobre os dados presentes na memória. As principais estruturas são: pilha, fila, lista, árvore e hashing. Dentre as estruturas mencionadas, a estrutura escolhida para ser explorada neste artigo é a estrutura de dados do tipo árvore, que consiste em nós conectados por arestas. Os elementos dos nós são representados por uma hierarquia e estabelecem relacionamentos lógicos. Os tipos de árvore utilizadas no trabalho são: Árvore binária e AVL.

Segundo Ascencio e Araújo (2010) uma árvore binária é um conjunto de elementos em que o nó acima dos demais chama-se nó raiz. Essa árvore poderá ser nula se apresentar apenas o nó raiz em sua distribuição. Se a partir da raiz existirem mais nós, esses são divididos em subárvores, sendo essas: subárvore da esquerda (contém nós com elementos de valor abaixo do elemento que está na raiz), e subárvore da direita (contém nós com elementos de valor acima do elemento que está na raiz). 


\section{CBIE-LACLO 2015}

Anais dos Workshops do IV Congresso Brasileiro de Informática na Educação (CBIE 2015)

Ainda de acordo com Ascencio e Araújo (2010) uma árvore AVL consiste em uma árvore binária já balanceada, ou seja, respeitando as suas normas para com o balanceamento. Também apresenta em seus nós uma determinada diferença de altura entre as subárvores da esquerda e direita, sendo essa diferença variando entre -1, 0 e 1.

Caso essa diferença de altura esteja abaixo de -1 ou acima de 1 , a árvore está violando suas normas de balanceamento, sendo assim denominada desbalanceada. Para que a árvore esteja balanceada corretamente, é necessário que aconteça algumas rotações em determinados nós e/ou sua raiz, para que a árvore possa respeitar suas normas e estar devidamente balanceada.

\section{Trabalhos Relacionados}

Muitos trabalhos voltados para a utilização de jogos como auxílio aos estudantes no contexto educacional têm sido desenvolvidos. Para o desenvolvimento desta proposta, alguns trabalhos foram analisados com o intuito de adquirir conhecimentos a partir desses, para assim, ser feita a formulação do jogo. A seguir serão descritos alguns trabalhos relevantes para a pesquisa.

Silva e Martins (2007) apresentam uma abordagem de ensino das principais disciplinas de um curso típico de graduação na área de Ciência da Computação. Os autores apontam que uma das possíveis causas do desinteresse e desmotivação apresentada pelos alunos é o interesse apenas em disciplinas específicas do curso, desvalorizando o conjunto de todas as disciplinas da grade curricular. Outra possível causa é que alunos estudam "pela nota", ou seja, sem o objetivo de construírem conhecimento. Consequentemente, os egressos tornam-se profissionais incompletos. Os professores estudaram diversas metodologias para despertar o interesse e motivação dos alunos, para que os mesmos possuam a consciência da importância de cada disciplina. A metodologia que fora encontrada e aplicada foi o desenvolvimento de jogos, pois segundo os autores, o motivo que leva alguém a desenvolver um jogo é a curiosidade e, isso faz com que os estudantes venham a pensar e estudar conceitos que anteriormente não despertavam tanto interesse e consequentemente motivação.

O trabalho de Thiry, Zoucas e Gonçalves (2010) apresenta uma solução para uma das principais falhas em projetos de desenvolvimento de softwares, que ocorre na etapa da Engenharia de Requisitos. Os autores alegam que parte dos estudantes que entram no mundo do trabalho possui pouca ou nenhuma experiência para exercer a função de analistas de requisitos. A possível causa apontada pelos autores é que durante o período de graduação, o ensino de técnicas de engenharia de requisitos é extremamente voltado para a teoria através de aulas palestradas. Consequentemente, os alunos desmotivam-se por não serem envolvidos em situações que ocorrem em projetos reais, resultando em despreparo para executar as atividades referentes a essa área. A solução apresentada foi um jogo educativo, desenvolvido em meio digital e visa proporcionar uma aprendizagem natural dos processos de Engenharia de Requisitos. $\mathrm{O}$ jogo foi aplicado em uma turma composta por 31 alunos e, conforme os autores foram obtidos resultados satisfatórios.

Já Souza et al. (2010), caracterizam o método de ensino teórico de engenharia de software como fator desmotivador na aprendizagem dos alunos em cursos de graduação. Decorrente deste fator, os alunos mostram-se desmotivados por não compreenderem os 


\section{CBIE-LACLO 2015}

Anais dos Workshops do IV Congresso Brasileiro de Informática na Educação (CBIE 2015)

problemas que podem acontecer no mundo real, as principais causas e práticas. Alguns estudos revelam que apenas o conhecimento de conceitos teóricos indispensáveis não é suficiente para que os acadêmicos estejam devidamente preparados para a realidade que irão encontrar no mundo do trabalho, pois a área de engenharia de software tem sua natureza extremamente prática, principalmente com relação às tomadas de decisões em ambientes instáveis. O trabalho foi realizado para tentar fornecer uma alternativa que abrangesse mais práticas no ensino da disciplina, haja vista que, no mundo do trabalho a aplicação dos conhecimentos construídos nessa disciplina são aplicados predominantemente de forma prática. Os autores apresentam um jogo denominado SPARSE, o qual fornece uma abordagem prática para o ensino e aprendizagem da disciplina de Engenharia de Software.

Diferentemente dos trabalhos apresentados, a proposta deste trabalho é construir um ambiente virtual gamificado, voltado inicialmente para a prática de conceitos de estruturas de dados, onde o aluno realizará uma série de atividades e receberá feedback do jogo instantaneamente na medida em que avança de fase. Para estabelecer a competição entre os jogadores, será implantada a funcionalidade "ranking" com a pontuação geral e/ou semanal. Também haverá um fórum de ajuda mútua e um chat, para que o aluno possa interagir com os demais jogadores e através da comunicação e troca de conhecimento sanar as suas dúvidas, estabelecendo também as relações de networking. A proposta visa propiciar uma construção sólida de conhecimentos por parte do aprendiz.

\section{Contextualização do Jogo}

A plataforma proposta neste artigo busca explorar a rede mundial de computadores, para assim, possibilitar acesso comum a todos os tipos de dispositivos, bem como pessoas que buscam maiores aprendizados em áreas específicas pertencentes ao ramo da computação.

Nesta seção será abordado o jogo em um contexto geral, esclarecendo primeiramente sua organização e posteriormente seu respectivo funcionamento. $\mathrm{O}$ diagrama representado na Figura 3 mostra o fluxo de atividades possibilitadas pelo sistema, essas serão amplamente descritas no decorrer da seção.

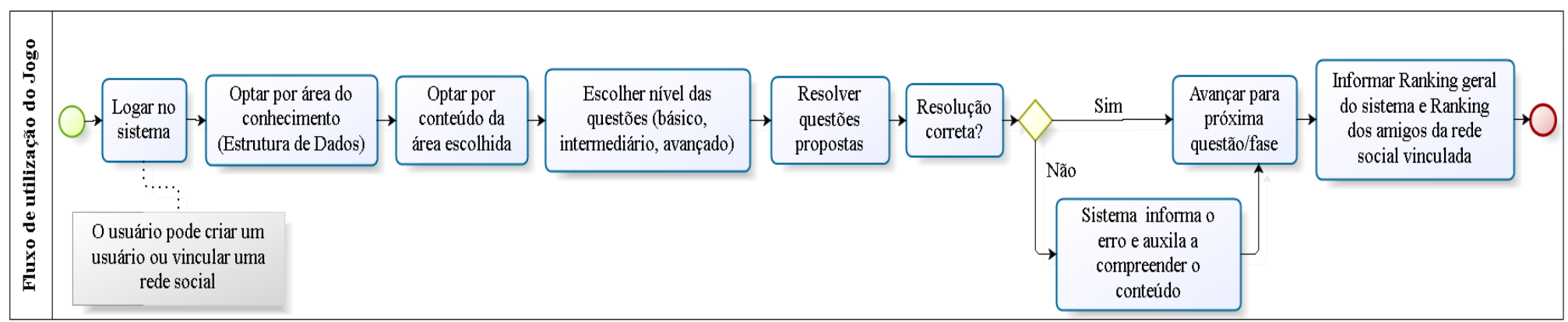

Figura 3. Fluxo de utilização do jogo

A organização será da seguinte maneira: na tela principal há diversos espaços referentes às áreas específicas pertencentes à computação. $O$ estudante opta pelo espaço que engloba a área de seu interesse e, ao acessá-la, a plataforma é redirecionada para 
uma página composta por seus respectivos conteúdos, esses organizados em três níveis: básico, intermediário e avançado.

Posteriormente, ele escolhe o nível, e após é apresentado uma descrição do conteúdo abordado pela atividade. O estudante deve abstrair os conteúdos que lhe são apresentados e, se incentivá-lo a aprofundar-se, poderá fazê-lo acessando a área que abrange maiores informações, essa disponibilizando bibliografias específicas. Embora o estudante possa acessar e desfrutar de diversos materiais de apoio e também solucionar exercícios, ainda pode (e deve) surgir dúvidas com relação aos conceitos, materiais e/ou exercícios. Consequentemente, é destinado um espaço para um fórum, que possui como objetivo estabelecer a comunicação entre os estudantes integrantes de um mesmo jogo. Essa comunicação tem por finalidade sanar as dúvidas que o estudante apresenta durante o seu processo de aprendizagem através da troca de informações entre os usuários.

Além do fórum para ajuda mútua, também é ofertado ao estudante um chat que visa a interação com os demais integrantes de um mesmo jogo da plataforma. $\mathrm{O}$ estudante pode visualizar os demais usuários que estão disponíveis para realizar trocas de informações e, tanto o chat quanto o fórum devem proporcionar ao usuário a exploração das relações de networking.

Com relação ao funcionamento do jogo, ao ser feito o primeiro acesso à plataforma, é solicitado a criação de um nome de usuário e senha, posteriormente permitindo a elaboração de um ranking personalizado ao aluno, bem como histórico de conquistas e ranking geral dos usuários integrantes da aplicação.

Após a criação do usuário, é possível começar a jogar. Para exemplificar o jogo, é abordado a seguir o seu funcionamento por meio de exercícios pertencentes à área de estrutura de dados baseadas em árvores. Quando o jogo inicia, os primeiros exercícios devem proporcionar ao jogador uma breve demonstração de como é realizada a distribuição dos elementos em uma árvore (Figura 4).

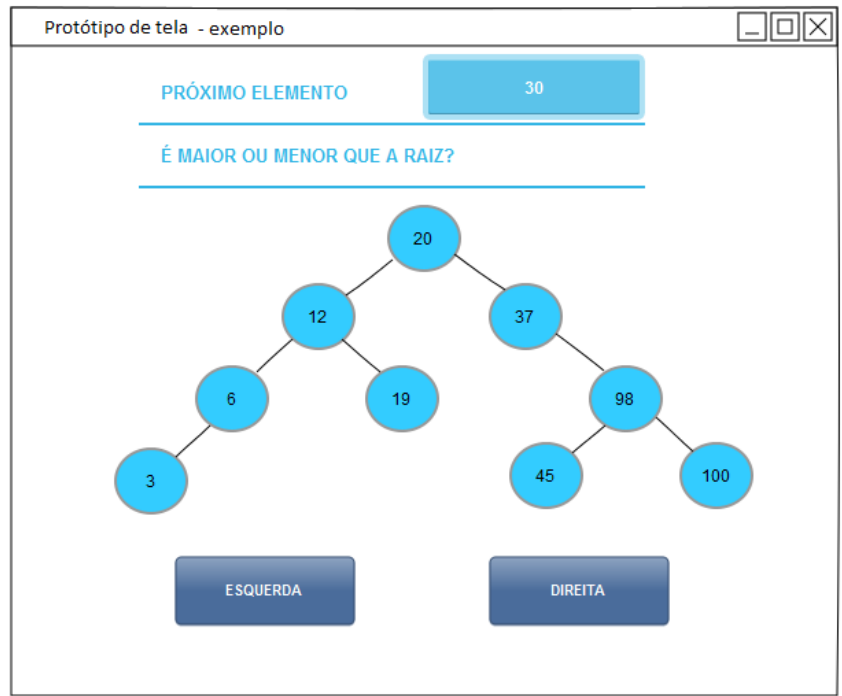

Figura 4. Exercício de distribuição de elementos em uma árvore

Posteriormente, são apresentadas as demais estruturas, onde todas possuem algum tipo de erro, sejam eles na ordenação ou balanceamento. O objetivo do jogador é 
encontrar a inexatidão presente na respectiva árvore e realizar os passos necessários para que aconteça o balanceamento eficiente da mesma (Figura 5).

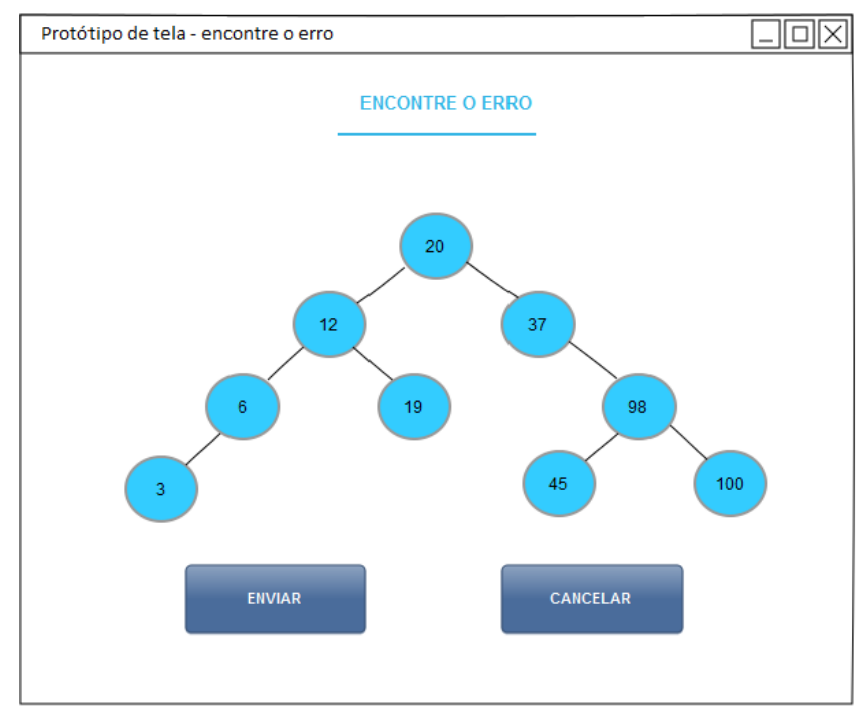

Figura 5. Representação de exercício do jogo

Após as rotações e os balanceamentos serem concluídos com sucesso, o jogador soma determinada quantia de pontos e avança para a próxima fase. Sendo fruto da capacidade de abstração dos conceitos introdutórios aliados à prática de solucionar exercícios, na medida em que o jogador avança de fase, deverão ser apresentadas ao mesmo, algumas mensagens para instigá-lo aos próximos desafios, bem como sua pontuação (Figura 6).

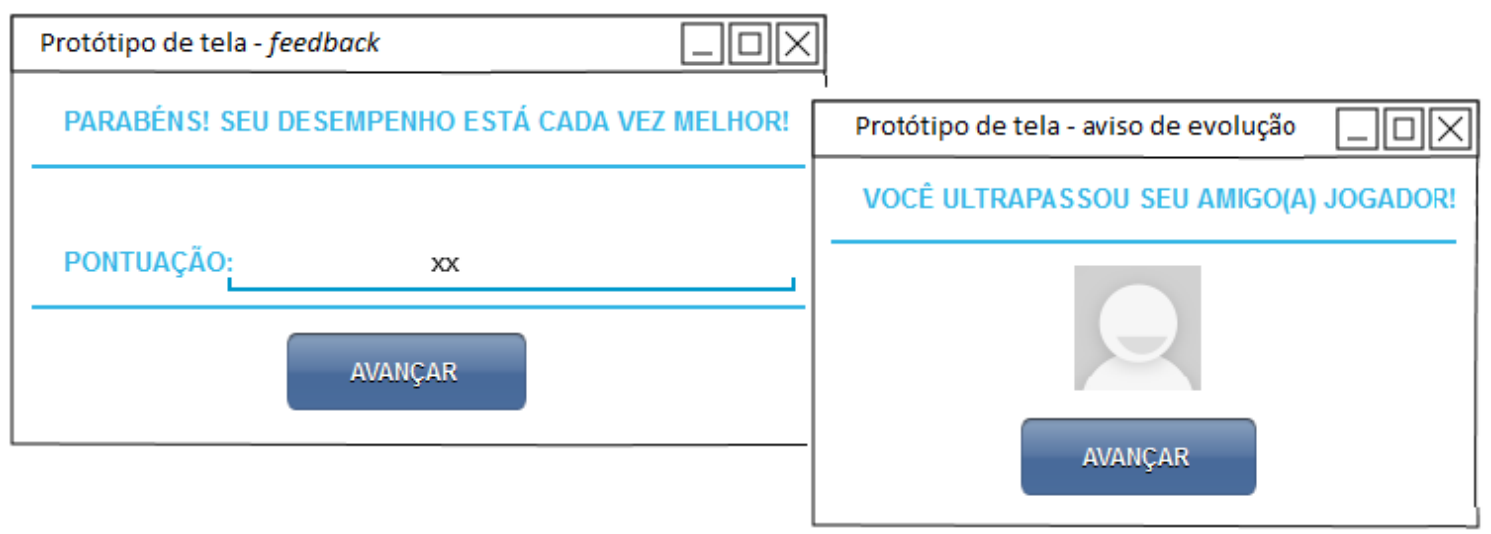

Figura 6. Telas de feedback positivo do jogo quanto ao desempenho do jogador e mensagem informando que o jogador ultrapassou um "concorrente"

O nível de complexidade dos exercícios eleva-se gradativamente. Desta forma, o jogo propõe ao jogador o estímulo do seu raciocínio lógico, para que a cada fase o desafio seja mais atrativo. Com exercícios cada vez mais complexos, espera-se que os mesmos possam instigar nos estudantes a vontade de vencer esses desafios ainda maiores apresentados aos mesmos.

Caso o jogador cometa algum erro enquanto estiver solucionando o exercício, é informado ao mesmo, tanto onde ele cometeu o erro como também algumas dicas de 
revisão baseadas nos conceitos abordados. Com esse feedback imediato o jogador pode visualizar e compreender os seus erros para resolver os respectivos desafios, estabelecendo um vínculo entre os fundamentos básicos apresentados pela área e a prática de resolução de exercícios.

É possível também criar grupos e adicionar jogadores, para que o jogador possa desafiar os demais membros e assim proporcionar a motivação dos usuários para solucionar problemas e incentivar a competição sadia através dos passos de construção do conhecimento pelos usuários. Para que a competição incentive a disputa, é informado ao jogador quando o mesmo ultrapassa os demais jogadores no somatório de pontos (Figura 6).

A competição propiciada pelo jogo dá-se através de rankings, sendo esses tanto gerais, ou seja, todos os jogadores participantes de uma determinada área ou de todos os jogadores que utilizam a plataforma para praticar seus conhecimentos, como também serão específicos, possibilitando assim uma competição entre amigos. A pontuação é recebida de acordo com o a tarefa realizada, assim contabilizando o número de acertos, os quais são acrescidos na pontuação do utilizador, de acordo com as especificações do ranking.

\section{Considerações Finais}

A área de estruturas de dados é complexa por exigir um grau elevado de abstrações de conteúdos, por parte dos estudantes. A utilização de jogos como auxílio para o ensino e aprendizagem ajuda a suprir as necessidades de práticas por parte dos discentes.

Este artigo propôs um jogo de cunho educacional para a área de estrutura de dados, buscando complementar o processo de construção do conhecimento por parte dos estudantes. O jogo proposto tem como intuito possibilitar uma competição atrativa, para através desta característica encontrada em jogos, despertar o interesse dos discentes.

Como trabalhos futuros, pretende-se concluir o desenvolvimento do jogo, introduzindo artefatos gráficos mais sofisticados com uso de Heads-Up Display (HUD), para assim, atrair, animar e informar os alunos utilizadores do mesmo. Outro ponto a ser implementado futuramente é a inserção de recompensas e danos. Ainda, realizar a validação do jogo, utilizando-o com alunos da disciplina de Estrutura de Dados. A partir disso, planeja-se coletar e analisar as opiniões dos mesmos, bem como professores, objetivando realizar melhorias a fim de aprimorar a qualidade do jogo e consequentemente a construção do conhecimento proporcionado pelo mesmo. Por fim, expandir a plataforma para outras áreas da computação, buscando fazer com que um dia ela se torne uma aliada da metodologia tradicional de ensino, auxiliando na prática de conteúdos de toda e qualquer disciplina dessas áreas.

\section{Referências}

ASCENCIO, A. F. G.; ARAUJO, G. S. Estruturas de Dados: algoritmos, análise da complexidade e implementações em JAVA e C/C++. São Paulo: Pearson PrenticeHall, v. 3, 2010.

BIGGS, J. B. Teaching for Quality Learning at University: What the Student Does. McGraw-Hill Education (UK), 2011. 
CBIE-LACLO 2015

Anais dos Workshops do IV Congresso Brasileiro de Informática na Educação (CBIE 2015)

BONWELL, C. C.; EISON, J. A. Active Learning: Creating Excitement in the Classroom. 1991 ASHE-ERIC Higher Education Reports. Washington, DC: ERIC, 1991.

CORMEN, T. H.; LEISERSON, C. E.; RIVEST, R. L. Introduction to Algorithms. 3. ed. United States: MIT Press, 2009.

DE ANDRÉA PICOLLI, C.; SPERS, E. E.; DE MORAES, S. G. A reconstrução de um plano de ensino: uma investigação sobre estilos e habilidades de aprendizagem. RACERevista de Administração, Contabilidade e Economia, v. 12, n. 3, p. 227-264, 2014.

DEMPSEY, J.; RASMUSSEN, K.; LUCASSEN, B. The instructional gaming literature: Implications and 99 sources. COE Technical report 96-1. University of South Alabama, p. 1-63, 1996.

DJAJALAKSANA, Y. A national survey of instructional strategies used to teach information systems courses: An exploratory investigation. Doctoral dissertation. University of South Florida, 2001.

GLOBO. Levantamento realizado pela Semesp. Disponível em: http://g1.globo.com/sp/sao-carlos-regiao/noticia/2012/09/indice-de-evasao-de-alunos-emaior-na-area-de-tecnologia-da-informacao.html. Visitado em Junho de 2015.

LAFORE, R. T. Estruturas de dados \& algoritmos em Java. Rio de Janeiro: CIÊNCIA MODERNA, 2005.

PFAHL, D., KOVAL, N., RUHE, G. An experiment for evaluating the effectiveness of using a system dynamics simulation model in software project management education. In: Proceedings of 7th METRICS Symposium, p. 97-109, 2001.

SHAW, K.; DERMOUDY, J. Engendering an Empathy for Software Engineering. In: Proc. Seventh Australian Computing Education Conference, p. 135-144, 2005.

SILVA, R. E. D.; MARTINS, S. W. Ensino de Ciência da Computação através do Desenvolvimento de Jogos. In: VII Congresso Iberoamericano de Informática Educativa, p. 1286-1295, 2007.

SOUZA, M. M.; RESENDE R. F.; PRADO L. S.; FONSECA, E. F.; CARVALHO, F. A.; RODRIGUES, A. D. SPARSE: Um Ambiente de Ensino e Aprendizado de Engenharia de Software Baseado em Jogos e Simulação. In: XXI Simpósio Brasileiro de Informática na Educação, 2010.

THIRY, M.; ZOUCAS, A.; GONÇALVES, R. Promovendo a Aprendizagem de Engenharia de Requisitos de Software através de um Jogo Educativo. In: XXI Simpósio Brasileiro de Informática na Educação, 2010.

VON WANGENHEIM, C. G.; VON WANGENHEIM, A. Ensinando Computação com Jogos. Bookess, , 2012. 